\title{
Non-Familial Synchronous Bilateral Renal Cell Carcinoma with Bilateral Synchronous Renal Vein Extension and Inferior Vena Cava Thrombus
}

\author{
Wilson Lin ${ }^{\mathrm{a}} \quad$ Kara L. Watts ${ }^{\mathrm{a}, \mathrm{b}} \quad$ Meenakshi Davulurib ${ }^{\mathrm{b}} \quad$ Ahmed Aboumohamed $^{\mathrm{a}, \mathrm{b}}$ \\ ${ }^{a}$ Albert Einstein College of Medicine; bontefiore Medical Center, Department of Urology, Bronx, NY, USA
}

\section{Key Words}

Bilateral radical nephrectomy • Tumor thrombectomy • Bilateral renal cell carcinoma $\cdot$ Renal vein tumor thrombi • Inferior vena cava tumor thrombus

\section{Abstract \\ Bilateral renal cell carcinoma with tumor thrombus exten- sion into the renal vein and/or inferior vena cava - clinical stage T3a+ - is rare. The majority of these cases arise due to a genetic predisposition. We present a case report of a 47-year-old male with bilateral, synchronous renal cell carci- noma with bilateral renal vein and inferior vena cava tumor thrombi with no identifiable familial predisposition.}

\section{(c) 2019 The Author(s)}

Published by S. Karger AG, Basel

\section{Introduction}

Bilateral synchronous renal cell carcinoma (RCC) is a rare entity, occurring in less than $5 \%$ of all RCC cases [1]. The majority are associated with hereditary familial syndromes, such as von Hippel-Lindau [1]. Only 4-10\% of all RCCs involve tumor thrombus extension into the renal vein and/or inferior vena cava (IVC) [2]. We describe a 47-year-old male who presented with nonfamilial synchronous bilateral RCC with bilateral synchronous renal vein extension and IVC thrombus. To our knowledge, this is the only reported case of bilateral synchronous venous extension of bilateral clear cell RCC.

\section{KARGER}

Fax +4161306 1234

E-Mail karger@karger.com

www.karger.com
(C) 2019 The Author(s)

Open access

This article is licensed under the Creative Commons AttributionNonCommercial-NoDerivatives 4.0 International License (CC BYNC-ND) (http://www.karger.com/Services/OpenAccessLicense). Usage and distribution for commercial purposes as well as any distribution of modified material requires written permission.

\section{Case Report}

A 47-year-old obese male with hypertension, anxiety, depression, alcohol abuse, and a 36-year history of tobacco use presented with gross hematuria. He had no reported history suggestive of any familial RCC syndromes. Computerized tomography scan (fig. 1) revealed a $10 \times 7.3 \mathrm{~cm}$ enhancing infiltrative tumor in the upper pole of the right kidney with a tumor thrombus extending into the IVC below the liver (level I). A concomitant $5 \times 4.5 \mathrm{~cm}$ enhancing infiltrative tumor in the left kidney with tumor thrombus into the left renal vein and a $2 \times 1.4 \mathrm{~cm}$ left adrenal nodule concerning for metastasis were present. Bilateral multiple smaller renal masses were also present.

The patient underwent open bilateral radical nephrectomy with IVC tumor thrombectomy and left renal vein tumor thrombectomy. He was started on hemodialysis on postoperative day 1 and did not have any significant postoperative complications. His pathology revealed bilateral clear cell RCC, Fuhrman grade 3, with metastasis to the left adrenal gland; pT3b N0M0 and pT3a N0M1 on the right and left, respectively. This pattern of tumor spread highlights the rare, heterogeneous, and aggressive behavior of clear cell RCC.

\section{Discussion}

RCC constitutes $2-3 \%$ of all cancers in the United States, with approximately 65,000 new cases and 13,000 deaths due to RCC occurring in the country each year [2]. Bilateral RCC accounts for only $1-5 \%$ of all cases of RCC and frequently arises due to hereditary predisposition [1]. Indeed, Gudbjartsson et al. [3] found a genetic etiology in nearly $60 \%$. Hereditary forms of the 


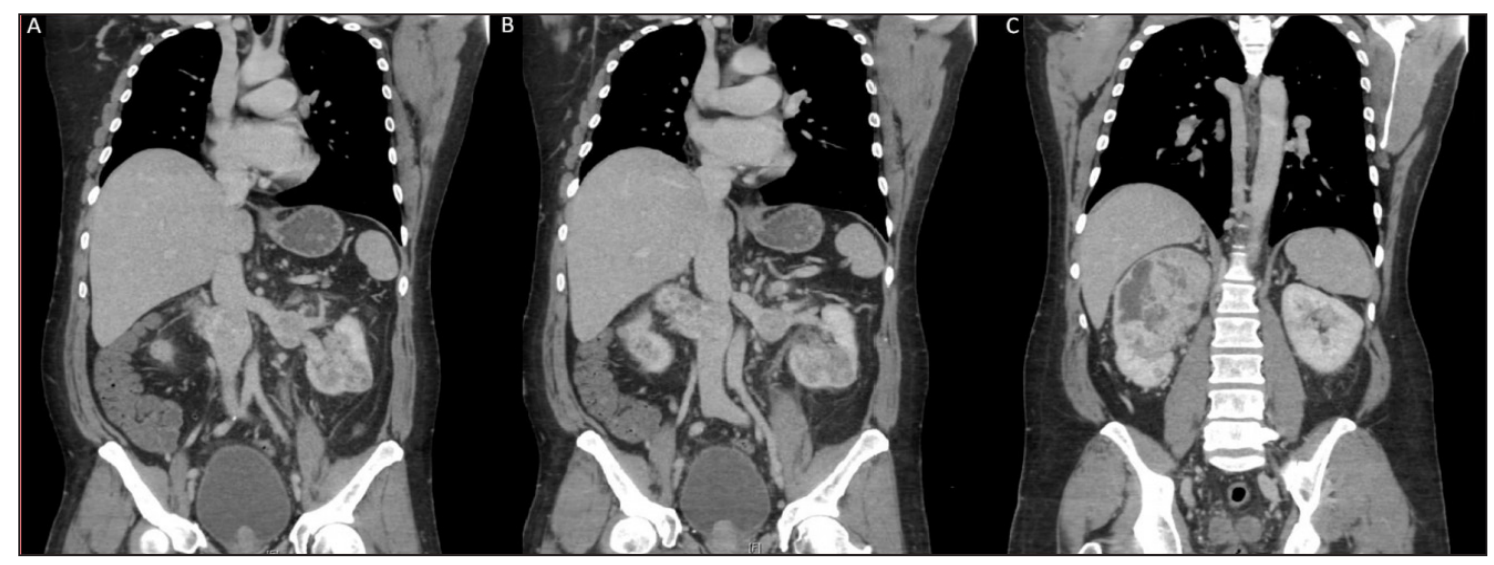

Fig. 1. A left lower and mid-polar enhancing renal mass with left renal vein extension; B Bilateral venous extension, with the left renal mass spreading into the left renal vein and the right renal mass extending into the IVC; C Large enhancing right renal mass replacing most of the right kidney.

disease have different intrinsic biological behavior compared to sporadic, non-familial bilateral RCC, with the former tending to occur in a multifocal manner and at a younger age [4]. Presentation similar to our case with young age and no family history of renal cancer or RCC familial syndromes is exceptionally rare. Additionally, just $4-10 \%$ of RCCs involve tumor thrombus extension into the renal vein and IVC [2]. To our knowledge, no published reports of concomitant bilateral thrombus extension (clinical stage $\mathrm{T} 3 \mathrm{a}+$ ) exists in the literature, thus making our case a unique presentation of the disease.

Surgery is the treatment of choice for sporadic bilateral RCCs as it has been shown to progress similarly to unilateral RCC and may have a similar prognosis [5]. Patients with bilateral RCCs without tumor thrombus often undergo nephron-sparing surgery given the importance of renal preservation, and particularly the association between chronic kidney disease and risk of cardiovascular events and death [5]. Surgeons must balance the need for complete eradication of malignant tissue with maintenance of renal function [4]. Options include radical nephrectomy of the kidney bearing large or multiple tumors followed by partial nephrectomy of the contralateral kidney harboring a smaller tumor burden, or bilateral partial nephrectomies for bilateral small tumors [4]. The surgery can be done in either a single setting or a staged setting. Small cohort studies have not shown a significant difference in tumor recurrence, postoperative complications, or length-of-stay when comparing single versus staged procedures. Therefore, tumor removal may be safely done in a single surgery, decreasing the risk associated with a second procedure [6].

For RCCs with tumor thrombus extension (clinical stage cT3a or higher), treatment typically involves radical nephrectomy and tumor thrombectomy. Median survival for patients who do not receive treatment is only 5 months; the 5-year survival rate for those who undergo incomplete tumor resection is approximately $10 \%[7,8]$. However, complete surgical resection results in a 5-year survival rate of up to $60 \%$ in some series [7]. An open approach has traditionally been favored, although minimally-invasive approaches using both hand- or robot-assisted laparoscopic techniques have been increasingly very selectively utilized [9]. Due to the fact that our patient had large bilateral RCCs with tumor thrombi extending into the renal vein and IVC on the left and right sides, respectively, nephron sparing was not feasible and he required a bilateral radical nephrectomy with tumor thrombectomy. He remains without evidence of recurrence at present. 


\section{References}

1 Qi N, Li T, Ning X, Peng X, Cai L, Gong $\mathrm{K}$ : Clinicopathologic features and prognosis of sporadic bilateral renal cell carcinoma: a series of 148 cases. Clin Genitourin Cancer 2017;15:618-624.

-2 Agochukwu N, ShuchB:Clinical management of renal cell carcinoma with venous tumor thrombus. World J Urol 2014;32:581-589.

-3 Gudbjartsson T, Jonasdottir TJ, Thoroddsen A, Einarsson GV, Jónsdóttir GM, Kristjánsson K, Hardarson S, Magnússon K, Gulcher J, Stefánsson K, Amundadóttir LT: A population-based familial aggregation analysis indicates genetic contribution in a majority of renal cell carcinomas. Int J Cancer 2002; 100:476-479.
-4 Grimaldi G, Reuter V, Russo P: Bilateral nonfamilial renal cell carcinoma. Ann Surg Oncol 1998;5:548-552.

-5 Wang B, Gong H, Zhang X, Li H, Ma X, Song E, Gao J, Dong J: Bilateral synchronous sporadic renal cell carcinoma: retroperitoneoscopic strategies and intermediate outcomes of 60 patients. PLoS One 2016;11:e0154578.

6 Jacobs BL, Gibbons EP, Gayed BA, Whetstone JL, Hrebinko RL: Management of bilateral synchronous renal cell carcinoma in a single versus staged procedure. Can J Urol 2009;16:4507-4511.
7 Hevia V, Ciancio G, Gomez V, Alvarez S, Diez-Nicolas V, Burgos FJ: Surgical technique for the treatment of renal cell carcinoma with inferior vena cava tumor thrombus: tips, tricks, and oncological results. Springerplus 2016;5:132.

8 Quencer KB, Friedman T, Sheth R, Oklu R: Tumor thrombus: incidence, imaging, prognosis, and treatment. Cardiovasc Diagn Ther 2017:7(suppl 3):S165-177.

-9 Psutka SP, Leibovich BC: Management of inferior vena cava tumor thrombus in locally advanced renal cell carcinoma. Ther Adv Urol 2015;7:216-229. 